\title{
Fosfomycin Protects Intestinal Cells from Nuclear Changes Suggestive of Deoxynivalenol-induced Apoptosis
}

\begin{abstract}
Background: Fosfomycin (FOS) is a broad-spectrum antibiotic that inhibits cell wall synthesis. It has bactericidal activity against both gram-positive and gram-negative bacteria. FOS also promotes phagocytosis, has immunomodulatory effects, and protects against the toxicity caused by other drugs. On the contrary, deoxynivalenol (DON) causes cytotoxicity on tissues of rapid growth and fast turnover. Objectives: The aim of this study was to determine the percentage of nuclear changes indicative of DONinduced apoptosis on intestinal cell cultures (Caco-2) and to evaluate the protective effect of FOS on mycotoxin-exposed cells. Materials and Methods: Cell cultures were treated as follows: (1) DON: 2.8 $\mu \mathrm{g} / \mathrm{mL}$, (2) calcium FOS: $580 \mu \mathrm{g} / \mathrm{mL}$, (3) DON $2.8 \mu \mathrm{g} / \mathrm{mL}+$ calcium FOS $580 \mu \mathrm{g} / \mathrm{mL}$, and (4) negative control. Nuclear morphology was evaluated in fixed cells stained with 4',6-diamino-2-phenylindol and then visualized under an immunofluorescence microscope. Results: Percentages of cells with nuclear changes were significantly higher in cells treated with DON $(31.53 \% \pm 4.17 \%)$ compared to those incubated with the antibiotic in conjunction with the mycotoxin $(5.63 \% \pm 4.23 \%)$. On the contrary, there were no significant differences between cells incubated with DON + FOS and cells incubated only with the antibiotic $(1.10 \% \pm 1.55 \%)$ when compared to the negative control $(3.50 \% \pm 0.09 \%)$. Conclusion: The results from this study showed that DON induces nuclear changes suggestive of apoptosis in intestinal cells and that FOS can protect cells from DNA damage. Further studies are needed to determine whether DON induces apoptosis only on cells of epithelial origin and to understand the implications of FOS protective effect under in vivo conditions.
\end{abstract}

Keywords: Apoptosis, deoxynivalenol, fosfomycin, intestinal cells, protective effect

\section{Introduction}

Deoxynivalenol (DON) is a mycotoxin with cytotoxic activity on rapidly growing tissues..$^{[1]}$ This mycotoxin results from the secondary metabolism of different strains of filamentous fungi, mainly Fusarium graminearum and Fusarium sporotrichioides. DON is a trichothecene (TCT) and due to its emetic effect, it is also known as "vomitoxin." [2] DON is a contaminant of crops used in food production for both human and animal use. ${ }^{[3]}$

Mycotoxins are regarded as an important risk factor for human and animal health. The gastrointestinal tract is the first physiological barrier against food contaminants, as well as the first target for these toxicants. An increasing number of studies suggest that intestinal epithelial cells are targets for DON and other Type B TCT. In humans, various adverse digestive symptoms are observed on acute exposure, and in animals, these toxins induce pathological lesions, including

This is an open access journal, and articles are distributed under the terms of the Creative Commons Attribution-NonCommercialShareAlike 4.0 License, which allows others to remix, tweak, and build upon the work non-commercially, as long as appropriate credit is given and the new creations are licensed under the identical terms.

For reprints contact: reprints@medknow.com necrosis of the intestinal epithelium. They affect the integrity of the intestinal epithelium by inducing alterations in cell morphology and differentiation and in the barrier function. Moreover, DON and Type B TCT modulate the activity of intestinal epithelium in its role in immune responsiveness. ${ }^{[4]}$

Besides the cytotoxicity on tissues of rapid growth and fast turnover, the main mechanism involved in the toxic action of DON is the inhibition of protein synthesis..$^{[1,5]}$ Particularly, the intestinal tract and immune cells are highly sensitive to DON. ${ }^{[6]}$ It has been shown that in these cell types DON induces DNA damage and apoptosis. ${ }^{[7,8]}$ Because ribosomes are the primary molecular target for TCT, including DON, translational inhibition is an obvious mechanism of toxicity. ${ }^{[9]}$ DON and other translational ribosome-binding inhibitors can rapidly activate mitogen-activated kinases (mitogen-activated protein kinases [MAPKs]), which are crucial for signal transduction in the immune respons $\mathrm{e}^{[10]}$ and they modulate numerous physiological processes including

How to cite this article: Perez Gaudio D, Mozo J, Martínez G, Fernández Paggi MB, Decundo JM, Romanelli $A$, et al. Fosfomycin protects intestinal cells from nuclear changes suggestive of deoxynivalenolinduced apoptosis. J Rep Pharma Sci 2020;9:209-14.

\section{Denisa \\ Pérez Gaudio ${ }^{1,2}$, Joaquín Mozo ${ }^{3}$, Guadalupe Martínez',2, María B. Fernández Paggi ${ }^{1,2}$, Julieta M. \\ Decundo ${ }^{1,2}$, Agustina Romanelli ${ }^{1,2}$, Susana Dieguez ${ }^{1,4}$, Alejandro Soraci $i^{1,2}$} I'Área de Toxicología, Depto. de Fisiopatología, Facultad de Ciencias Veterinarias, Universidad Nacional del Centro de la Provincia de Buenos Aires, Tandil, Argentina, ${ }^{2}$ Centro de Investigación Veterinaria de Tandil (CIVETANCONICET), Tandil, Argentina, ${ }_{3}^{3}$ Agencia Nacional de Promoción Científica y Tecnológica (ANPCyT), Ciudad Autónoma de Buenos Aires, Argentina, ${ }^{4}$ Comisión de Investigaciones Cientificas de la Provincia de Buenos Aires, La Plata, Argentina

Received: 15 Nov 2019 Accepted: 14 May 2020 Published: 07 Oct 2020

Address for correspondence: Dr. Denisa Pérez Gaudio, Centro de Investigación Veterinaria de Tandil, Facultad de Ciencias Veterinarias, Universidad Nacional del Centro de la Provincia de Buenos Aires, CP: (7000), Tandil, Buenos Aires, Argentina. E-mail:denisa@vet.unicen. edu.ar

Access this article online Website: www.jrpsjournal.com DOI:10.4103/jrptps.JRPTPS_124_19 Quick Response Code:

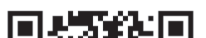

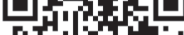

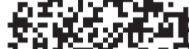
75 Fer

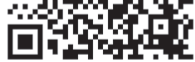


growth, differentiation, and apoptosis. ${ }^{[1]}$ The process by which TCT activates MAPK p38 is called the "ribotoxic stress response.' ${ }^{[12-14]}$ However, the exact mechanism by which DON damages DNA and promotes cellular toxicity is not yet well established. ${ }^{[15]}$ These kinases exert a regulatory effect on the activity of cellular proteins, and therefore emerge as an important target for the design of therapeutic drugs. ${ }^{[16]}$

The most important pathways used for DON detoxification is cytochrome P450, which serves to catalyze the oxidation of organic substances. This is the natural way that human and animal bodies use to metabolize the toxin. However, activation of this pathway may lead to the cleavage of free hydroxyl groups of DON resulting in the more dangerous DON radicals. DON radicals can be scavenged by enzymatic (glutathione peroxidase, catalase, superoxide dismutase) or nonenzymatic (reduced glutathione, metallothionein, and vitamins) mechanisms. ${ }^{[17]}$ In this regard, several natural components of the diet such as tocopherol, carotenoids, and ascorbic acid show antioxidant properties and may counteract mycotoxin cytotoxicity by blocking mycotoxin-induced free radical damage. ${ }^{[18]}$ Nevertheless, the results obtained with the use of natural antioxidants added to diets are contradictory. ${ }^{[19,20]}$

DON is a contaminant of wheat, corn, rice, barley, oats, and other cereal grains used in food production for human and animal use. However, people are not only exposed to mycotoxins by directly consuming grains and their derived products but also indirectly through foods of animal origin (kidney, liver, milk, and eggs). ${ }^{[17]}$

In this regard, this mycotoxin is among the antinutritional components present in the diets of production animals that negatively affect their productive performance. On the contrary, a very common practice in intensive animal production is the use of antibiotics, either as growth-promoting additives (incorporated into food or drinking water at subtherapeutic doses) or as therapeutic/metaphylactic agents with the aim of improving performance and reducing mortality. Even though, since 2006, the countries of the European Union decided to definitively ban the use of antibiotics in subtherapeutic doses in animal feed and considerably limit therapeutic indications, ${ }^{[21]}$ in other countries, it is still a very common practice. This is because its withdrawal is not possible yet due to the characteristics of some production systems and by hygiene and/or handling problems in the farms. Considering this, it is common in animal feed to find the combined presence of antibiotic additives that promote animal performance and subtoxic concentrations of antinutritional compounds such as mycotoxins. Once ingested, the intestine can be exposed to the interaction of both compounds.

Precisely, fosfomycin (FOS) is among these antibiotics incorporated in subtherapeutic doses in the diets of intensively produced animals in many countries of Asia and America. It is widely used in animal production due to its rapid effect, good tolerance, and lack of side effects. ${ }^{[22,23]}$ FOS is a broad-spectrum antibiotic ${ }^{[24]}$ with bactericidal activity against both gram-positive and gram-negative bacteria. ${ }^{[25,26]}$
When compared with other antibiotics, it has a broader in vitro spectrum of action than penicillins and semisynthetic cephalosporins. ${ }^{[25]}$ FOS (cis-1,2-epoxyphosphonic acid) is structurally unrelated to other classes of antimicrobial agents. FOS acts in proliferating bacteria by inhibition of cell wall and early murein/peptidoglycan synthesis. ${ }^{[27]}$ Its unique mechanism of action makes it useful for the treatment of human complicated urinary tract infections. ${ }^{[28]}$ It penetrates bacteria by two systems of permeases, one that transports $1-\alpha$-glycerol phosphate and other, which is inducible and takes d-glucose6-phosphate inside the bacterial cytoplasm. ${ }^{[24]}$ It inhibits an initial step in peptidoglycan synthesis, ${ }^{[29]}$ which is triggered by an analog of FOS, ${ }^{[24,27]}$ uridine diphosphate $N$-acetylglucosamine-enol-pyruvyl-transferase, and its co-enzyme, phosphoenolpyruvate (PEP). FOS acts on bacteria in the growth phase without interfering with the reactions requiring PEP in animal cells. This is because, in animals, an enzymatic attack occurs at a different place in PEP and the enzyme does not recognize FOS as a substrate. FOS inhibits the binding of PEP to $N$-acetylglucosamine. For cell wall synthesis, the group $-\mathrm{O}-\mathrm{PO}_{3} \mathrm{H}_{2}$ of PEP is separated, binding the pyruvate $\mathrm{C}_{2}$ to the oxygen of $\mathrm{N}$-acetylglucosamine. However, in eukaryotic cells, oxygen remains attached to $\mathrm{C}_{2}$, separating only the phosphate $\mathrm{PO}_{3} \mathrm{H}_{2}$. FOS has in its molecule the $-\mathrm{OCP}-$ sequence, which is different from the -OCP sequence of PEP. This fact explains the high selectivity of FOS, which inhibits the use of PEP during cell wall synthesis (where the enzyme cleaves OL binding) but does not affect the metabolism of eukaryotic cells (where enzymes break the OP bond). ${ }^{[30]}$

The acidic nature of FOS allows the rapid formation of salts. Calcium FOS salt is used orally, whereas the more water-soluble disodium salt can be administered intravenously. ${ }^{[7,13,14]}$ Other properties of this drug include inhibition of bacterial adhesion to epithelial cells, exopolysaccharide biofilm penetration, immunomodulatory effect, phagocytosis promotion, and protection against the nephrotoxicity caused by other drugs. ${ }^{[10]}$ It is not known how FOS exhibits these activities.

We have shown on previous researches that DON induces apoptosis in respiratory (Human Epidermoid carcinoma strain 2 (HEp-2) and Bovine Turbinate (BT)) and renal Madin-Darby bovine kidney (MDBK) cell lines and that FOS is able to prevent these damages. ${ }^{[31]}$ We hypothesize that FOS might have action on the MAPK p38 pathway, protecting cells from apoptosis induced by DON.

The aim of this work was to determine the presence and extent of nuclear alterations indicative of DON-induced apoptosis on intestinal cell cultures (Caco-2) and to evaluate the protective effect of FOS on mycotoxin-exposed cells.

\section{Materials and Methods}

\section{DON and FOS doses used for the experimental study}

As mycotoxin source, a pure standard of DON with a molecular weight of $296.32 \mathrm{~g} / \mathrm{mol}\left(\mathrm{C}_{15} \mathrm{H}_{20} \mathrm{O}_{6}\right)$ (Sigma-Aldrich, St Louis, MO, USA) was used. An $80-\mu \mathrm{g} / \mathrm{mL}$ DON stock 
solution was prepared in methanol. A $2.8 \mu \mathrm{g} / \mathrm{mL}$ dose of DON, previously determined by us $^{[31]}$ was used. In that study, we have determined that doses of 1.4 and $2.8 \mu \mathrm{g} / \mathrm{mL}$ of DON produce toxic effects on HEp-2 cells. Nevertheless, cells treated with the higher dose of the mycotoxin revealed a more evident presence of globoid cells and cytoplasmic membrane changes.

Calcium FOS salt (Fosbac, Bedson Lab., Argentina) was used for protection studies. In previous assays with other cells lines (HEp2, MDBK, BT, and Baby Hamster Kidney fibroblasts (BHK)), increasing doses of FOS $(75,100,150,200,300,400$, and $580 \mu \mathrm{g} /$ $\mathrm{mL}$ ) were evaluated whereas a $2.8 \mu \mathrm{g} / \mathrm{mL}$ dose of DON was used, as described previously. Complete protection against the effects of DON was achieved when all cell lines were incubated with the higher dose of FOS. Furthermore, we have determined that increasing doses of FOS protect respiratory and renal cells against a toxic dose of DON. ${ }^{[31]}$ According to these previous studies, a $580 \mu \mathrm{g} / \mathrm{mL}$ stock solution of calcium FOS was prepared in saline solution for protection studies on intestinal cells.

\section{Cell cultures}

For these experiments, Caco-2 (human epithelial colorectal adenocarcinoma) cells were used. This cell line was chosen as a target cell type since oral exposure is the common route of intoxication by DON. Moreover, the intestinal epithelium is characterized by rapid cell renewal and it is known to be one of the main target tissues for TCT toxicity. Derived from a colon carcinoma, the Caco-2 cell line is widely used as a model system for the study of enterocytic functions, ${ }^{[32]}$ and several studies on apoptosis have been conducted in this cell line using different apoptotic stimuli. ${ }^{[33-36]}$

Cells were grown in $75-\mathrm{cm}^{2}$ flasks with Eagle's minimal essential medium (E-MEM) and $20 \%$ of fetal bovine serum (FBS). At 24h, the medium was replaced (MEM and 10\% FBS) to allow cell division to continue up to a complete confluent monolayer. The medium was removed and cells were washed with phosphate buffer saline (PBS). Trypsin was added for $10 \mathrm{~min}$ at $37^{\circ} \mathrm{C}$. Detached cells were resuspended in PBS and centrifuged for $5 \mathrm{~min}$ at $1500 \mathrm{rpm}$. Cell pellet was resuspended in MEM with $10 \%$ FBS and transferred to new flasks. Cells were maintained in an incubator at $37^{\circ} \mathrm{C}$ and $5 \% \mathrm{CO}_{2}$ and seeded $\left(0.2 \times 10^{6}\right.$ cells $\left./ \mathrm{mL}\right)$ in 24 -well plates with coverslips for cell adhesion, as indicated below. After $24 \mathrm{~h}$ they were dosed according to the following treatments: (1) DON: $2.8 \mu \mathrm{g} / \mathrm{mL}$, (2) calcium FOS: $580 \mu \mathrm{g} / \mathrm{mL}$, (3) DON $2.8 \mu \mathrm{g} / \mathrm{mL}+$ calcium FOS $580 \mu \mathrm{g} / \mathrm{mL}$, and (4) negative control: cells with culture medium. Cell cultures were incubated for $4 \mathrm{~h}$ because in previous studies we have determined that this was the earlier timepoint at which cell detachment was observed when cells were incubated only with the mycotoxin at a dose of $2.8 \mu \mathrm{g} /$ $\mathrm{mL} .{ }^{[31]}$ Thus, after $4 \mathrm{~h}$, the medium was removed.

\section{Determination of nuclear changes by DAPI}

DAPI (4',6-diamino-2-phenylindol) is a nuclear stain used to evaluate morphological changes that can be visualized during

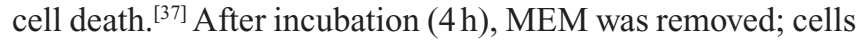

were washed with PBS and fixed with 4\% paraformaldehyde. To evaluate the presence of nuclear morphological changes representative of apoptosis, fixed cells were stained with DAPI and then visualized under an immunofluorescence microscope. The percentage of cells with altered nuclear morphology (nuclear condensation and chromatin fragmentation) was determined in duplicate for each experiment.

\section{Statistical analysis}

To determine differences in the number of apoptotic cells in each treatment group, an analysis of variance followed by the Tukey test was performed. Significant differences were observed when $P \leq 0.01$.

\section{Results}

The percentages of cells with nuclear changes were significantly higher $(P \leq 0.01)$ in cells treated with DON $(31.53 \% \pm 4.17 \%)$ compared to those incubated with the antibiotic in conjunction with the mycotoxin $(5.63 \% \pm 4.23 \%)$. On the contrary, there were no significant differences between cells incubated with $\mathrm{DON}+\mathrm{FOS}$ and cells incubated only with the antibiotic $(1.10 \%$ $\pm 1.55 \%)$ when compared to the negative control $(3.50 \% \pm$ $0.09 \%$ ) and low percentages of nuclear changes were observed in cells subjected to these treatments [Figure 1].

Figure 2 shows the immunofluorescence by DAPI staining of Caco-2 intestinal cells under the different treatments, magnification $\times 20$.

\section{Discussion}

There are no previous studies concerning the protective effect of FOS on intestinal tissues or cells. Since the 1980s, several studies regarding this role of the antibiotic have been performed. Particularly, FOS has been evaluated coadministered with aminoglycosides and cisplatin, and the results showed that it protects from ototoxicity and nephrotoxicity. Inouye et al. ${ }^{[38]}$ have shown in a murine model that FOS protects the proximal tubular lysosomes in the kidneys from the injury caused by aminoglycosides. This was evidenced in vivo by suppression of myeloid body formation and protection of the integrity of lysosomal membranes in the rats treated with dibekacin. Furthermore, they have shown that, in vitro, there is a dose-

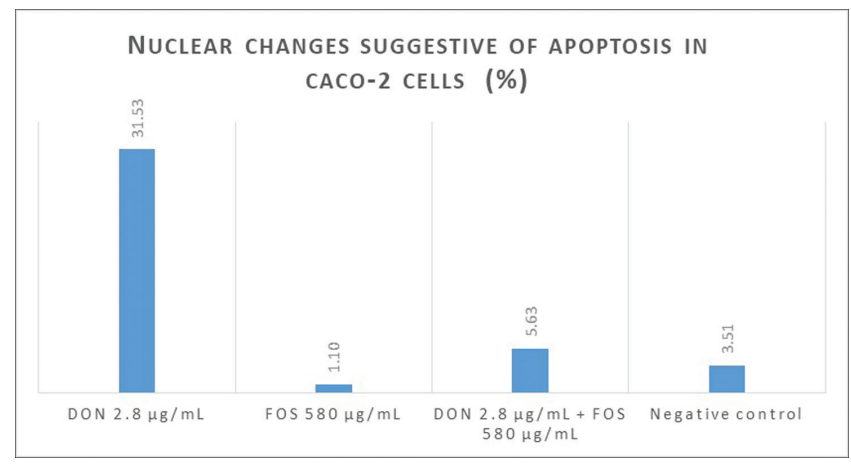

Figure 1: Nuclear changes suggestive of apoptosis in Caco-2 intestinal cells in the presence or absence of calcium FOS 


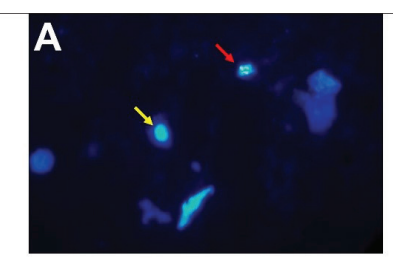

DON $2.8 \mu \mathrm{g} / \mathrm{mL}$

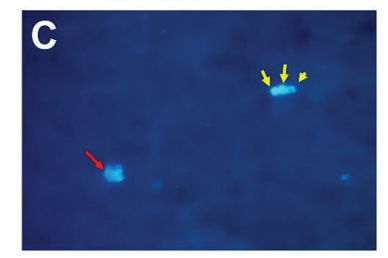

DON $2.8 \mu \mathrm{g} / \mathrm{mL}+$ FOS $580 \mu \mathrm{g} / \mathrm{mL}$

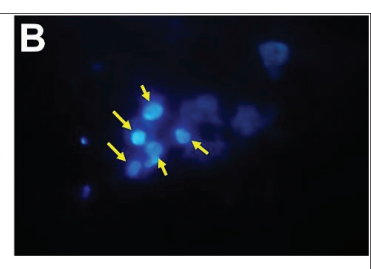

FOS $580 \mu \mathrm{g} / \mathrm{mL}$

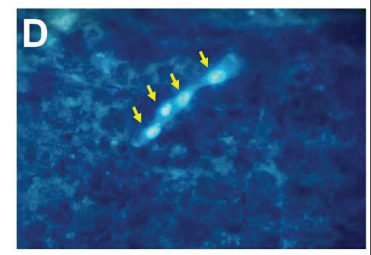

Negative control
Figure 2: Immunofluorescence microscopy (DAPI staining) of Caco-2 intestinal cells. (A) DON $2.8 \mu \mathrm{g} / \mathrm{mL}$, (B) FOS $580 \mu \mathrm{g} / \mathrm{mL}$, (C) FOS $580 \mu \mathrm{g} /$ $\mathrm{mL}+\mathrm{DON} 2.8 \mu \mathrm{g} / \mathrm{mL}$, and (D) negative control (red arrows = cells with nuclear changes representative of apoptosis, yellow arrows $=$ cells with normal nuclei)

dependent protection of the lysosomal membrane integrity of the kidney cells. A study of the structure-protective activity of FOS revealed that a phosphonate anion possessing an epoxy function was important for protection and that this mechanism was different from its antibacterial mechanism. The protective effect of FOS against aminoglycoside-induced ototoxicity was also studied in rats, and it was concluded that the mechanism of reduced ototoxicity was associated with the ability of FOS to inhibit the accumulation of dibekacin in the kidney and to reduce its concentration in the kidney and serum. Consequently, the amounts of dibekacin reaching the inner ear are decreased, and ototoxicity is reduced. ${ }^{[39]}$ It has been shown that FOS also inhibits gentamicin-induced lipid peroxidation by depressing iron release from mitochondria. It is likely that this is one of the mechanisms of FOS to protect against gentamicin-induced nephrotoxicity. ${ }^{[0]}$

Schweitzer et al. ${ }^{[41]}$ showed that FOS ameliorates acute renal tubular necrosis and interstitial nephritis and markedly inhibits the elevation of the auditory brain stem evoked response thresholds and outer hair cell loss that can result from cisplatin administration. They consider that FOS can be used as a potential antidote for the dose-limiting ototoxicity and nephrotoxicity of cisplatin. Tandy et al. ${ }^{[42]}$ showed that FOS does not inhibit the tumoricidal activity of this chemotherapeutic agent and that FOS in combination with cisplatin may be useful in treating advanced, and possibly relatively chemoresistant, squamous cell carcinoma of head and neck. They also found that mice treated with FOS had longer survival, which is probably due to lessening of immediate cisplatin systemic toxicity. Yingjun et al. ${ }^{[43]}$ also suggested that FOS may have additional or indirect mechanisms of protection, such as that observed in the prevention of cisplatin-induced hepatotoxicity, when FOS is used in combination with other agents such as selenium, methionine, taurine, and zinc.
All these studies are coincident in that the exact mechanism of FOS protection is not clear. However, stabilization of lysosomal membranes, interference with cellular uptake, and blockage of reactive sites on cell membranes are possible actions. ${ }^{[4]}$

Martínez et al., ${ }^{[45,46]}$ in 2011 and 2013, have studied FOS penetration on HEp-2 cells and pig intestinal cells (IPEC-J2), respectively. They demonstrated that, at no lethal doses, the mycotoxin DON does not alter the penetration of FOS into the cells. However, they found that the nontoxic concentration of DON on IPEC-J2 cells interferes with the pharmacokinetics of the antibiotic, which reaches lower intracellular concentrations. The authors suggested that DON modifies the sodium-iondependent phosphate transport that FOS uses to enter the cells, especially considering that it has been shown that DON affects the activities of the sodium-dependent glucose/galactose transporter (SGLT1), an intestinal transporter. ${ }^{[47]}$

Our results showed that DON induces nuclear changes indicative of apoptosis in intestinal cells and FOS protects against cell DNA damage induced by DON. These findings are consistent with our previous studies on BT, MDBK, and HEp-2 cells, ${ }^{[31]}$ in which cells incubated with DON $(2.8 \mu \mathrm{g} /$ $\mathrm{mL})$ and FOS $(550 \mu \mathrm{g} / \mathrm{mL})$ had none or minimal nuclear alterations similar to the negative control, indicating the absence of cytotoxicity. On the contrary, cells treated only with the mycotoxin had significantly higher rates of apoptosis (BT: $51.66 \pm 0.33$, MDBK: $10 \pm 0.00$, and HEp-2: $5.64 \pm 0.27)$, as observed in this study $(31.53 \pm 4.17)$.

DON has proven cytotoxicity on tissues of rapid growth and fast turnover, ${ }^{[1,3]}$ as we have shown for intestinal cells. The findings of this work show that intestinal cells are prone to cell death in the presence of DON, as we have previously found for HEp-2, MDBK, BT, and BHK cells. These results are in agreement with other in vivo ${ }^{[7]}$ and in vitro ${ }^{[48]}$ experiments showing that some cells are particularly sensitive to DON. As the ribosome is the primary molecular target for TCT, included DON, translational inhibition is an obvious mechanism of toxicity. ${ }^{[9]}$ DON and other ribosomebinding translational inhibitors can rapidly activate MAPKs, which are crucial for signal transduction in the immune response ${ }^{[10]}$ and modulate numerous physiological processes including cell growth, differentiation, and apoptosis. ${ }^{[1]}$ The process by which TCT activates MAPKs is termed the "ribotoxic stress response."[12,13] However, the exact mechanisms through which DON damages the DNA and promotes cellular toxicity are not yet well established. ${ }^{[15]}$

The precise pathway that leads to the protection achieved by FOS on DON-mediated cellular damage is still unknown. However, from this study and from our previous work on respiratory and renal cell lines, it is evident that the antibiotic is able to prevent the nuclear changes indicative of programmed cell death induced by DON. Our studies are initial steps in understanding these mechanisms and it reveals that the level of induction of apoptosis appears to be dependent on the cell type. Further studies are needed to understand the implications of this effect under in vivo conditions. 


\section{Conclusion}

The results from this study showed that DON induces nuclear changes suggestive of apoptosis in intestinal cells and that FOS can protect cells from DNA damage, as we have previously determined for other cell lines. Future investigations to determine the exact way in which FOS prevents DON-induced apoptosis may be of significance, especially when considering that the mycotoxin is responsible for ribotoxic stress response and that the antibiotic could be acting by preventing DON effects on MAPKs or other signaling pathways that trigger apoptotic death.

\section{Financial support and sponsorship}

This study was supported by the ANPCyT (Agencia Nacional de Promoción Científica y Tecnológica), Argentina.

\section{Conflicts of interest}

There are no conflicts of interest.

\section{References}

1. Desjardins AE. Fusarium Mycotoxins. Chemistry, Genetics and Biology. St. Paul, MN: American Phytopathology Society Press; 2006. p. 260.

2. Rotter BA, Thompson BK, Prelusky DB, Trenholm HL, Stewart B, Miller JD. Response of growing swine to dietary exposure to pure Fumonisin B1 during an eight-week period: Growth and clinical parameters. Nat Toxins 1996;4:42-50.

3. Tajehmiria A, Aliabadi MA, Darsanaki RK. Occurrence of deoxynivalenol in cereals and cereal based products: A short review. Scientific J Biol Sci 2014;3:1-5.

4. Pinton P, Oswald IP. Effect of deoxynivalenol and other type $\mathrm{B}$ trichothecenes on the intestine: A review. Toxins (Basel) 2014;6:1615-43.

5. Eriksen GS. Metabolism and Toxicity of Trichothecenes. Doctoral thesis. Upsala, Sweden: Swedish University of Agriculture Science; 2003.

6. Petska JJ. Mechanisms of deoxynivalenol-induced gene expression and apoptosis. Food Addit Contam Part A Chem Anal Control Expo Risk Assess. Special Issue: Proceedings of the 10th UJNR International Symposium on Toxic Microorganisms. 2008;25:112840.

7. Awad WA, Aschenbach JR, Setyabudi FMCS, Razzazi-Fazeli E, Böhm J. In vitro effects of deoxynivalenol on small intestinal Dglucose uptake and absorption of deoxynivalenol across the isolated jejunal epithelium of laying hens. Poult Sci 2007;86:15-20.

8. Savard C, Gagnon CA, Chorfi Y. Deoxynivalenol (DON) naturally contaminated feed impairs the immune response induced by porcine reproductive and respiratory syndrome virus (PRRSV) live attenuated vaccine. Vaccine 2015;33:3881-86.

9. Ueno Y. Toxicological features of T-2 toxin and related trichothecenes. Fundam Appl Toxicol 1984;4:S124-32.

10. Dong C, Davis RJ, Flavell RA. MAP kinases in the immune response. Annu Rev Immunol 2002;20:55-72.

11. Cobb MH. MAP kinase pathways. Prog Biophys Mol Biol 1999;71:479-500.

12. Iordanov MS, Pribnow D, Magun JL, Dinh TH, Pearson JA, Chen SL, et al. Ribotoxic stress response: Activation of the stress-activated protein kinase JNK1 by inhibitors of the peptidyl transferase reaction and by sequence-specific RNA damage to the alpha-sarcin/ricin loop in the 28S rRNA. Mol Cell Biol 1997;17:3373-81.
13. Laskin JD, Heck DE, Laskin DL. The ribotoxic stress response as a potential mechanism for MAP kinase activation in xenobiotic toxicity. Toxicol Sci 2002;69:289-91.

14. Lucioli J, Pintona P, Callud P, Laffitte J, Grosjeand F, KolfClauwb $\mathrm{M}$, et al. The food contaminant deoxynivalenol activates the mitogen activated protein kinases in the intestine: Interest of ex vivo models as an alternative to in vivo experiments. Toxicon 2013;66:31-6.

15. Singh S, Banerjee S, Chattopadhyay P, Borthakur SK, Veer V. Deoxynivalenol induces cytotoxicity and genotoxicity in animal primary cell culture. Toxicol Mech Methods 2015;25:184-91.

16. Ortiz Melón JM. Proteína quinasas como dianas farmacológicas. An Real Acad Farm 2009;75:15-45.

17. Sobrava P, Adam V, Vasatkova A, Beklova M, Zeman L, Kizek R. Deoxynivalenol and its toxicity. Interdiscip Toxicol 2010;3:94-9.

18. Galvano F, Piva A, Ritieni A, Galvano A. Dietary strategies to counteract the effects of mycotoxins: A review. J Food Prot $2001 ; 64: 120-31$

19. Mansour MK, Hassan AA, Rashid MA. The fungi recorded in imported feed samples with reference to control of T-2 toxicosis by antioxidant substances in chicks. Vet Med J Giza 2002;50:485-99.

20. Korošec TF, Janez S, Rezar V. The effect of vitamin E supplementation on reduction of lymphocyte DNA damage induced by T-2 toxin and deoxynivalenol in weaned pigs. Anim Feed Sci Technol 2008;141:274-86.

21. Diario Oficial de la Unión Europea. Directiva 1831/2003/EEC. Reglamento (CE) No 1831/2003 del Parlamento Europeo y del Consejo del 22 de septiembre de 2003 sobre los aditivos en la alimentación animal; 2003:L268:29-43.

22. Popovic M, Steinfort D, Pillai S, Joukhadar C. Fosfomycin: An old, new friend? Eur J Clin Microbiol Infect Dis 2010;29:127-42.

23. Gobernado M. Fosfomycin. Spanish J Chemother 2003;16:15-40.

24. Kahan FM, Kahan JS, Cassidy PJ, Kropp H. The mechanism of action of fosfomycin (phosphonomycin). Ann NY Acad Sci 1974;235:364-86.

25. Mata J, Rodriguez A, Gallego A. Fosfomycin: In vitro activity. Chemotherapy 1977;23:23-4.

26. Aramayona JJ, Bregante MA, Solans C, Rueda S, Fraile LJ, García MA. Pharmacokinetics of fosfomycin in chickens after a single intravenous dose and tissue levels following chronic oral administration. Vet Res 1997;6:581-8.

27. Carramiñana JJ, Rota C, Agustín I, Herrera A. High prevalence of multiple resistance to antibiotics in Salmonella serovars isolated from a poultry slaughterhouse in Spain. Vet Microbiol 2004;104:133-9.

28. Borsa F, Leroy A, Fillastre JP, Godin M, Moulin B. Comparative pharmacokinetics of tromethamine fosfomycin and calcium fosfomycin in young and elderly adults. Antimicrob Agents Chemother 1988;32:938-41.

29. Mensa J, Gatelí JM, Corachán M, Escofel MC, Martínez JA, Zamora L. Guía de Terapéutica Antimicrobiana. 4 ed. Barcelona, Spain: Científicas y Técnicas, S.A.; 1994.

30. Patel SS, Balfour JA, Bryson HM. Fosfomycin tromethamine. A review of its antibacterial activity, pharmacokinetic properties and therapeutic efficacy as a single-dose oral treatment for acute uncomplicated lower urinary tract infections. Drugs 1997;53:637-56.

31. Pérez Gaudio DS, Martínez G, Fernández Paggi MB, Riccio MB, Decundo JM, Dieguez SN, et al. Protective effect of fosfomycin in deoxynivalenol (DON)-treated cell cultures. Eur J Biomed Pharm Sci 2016;3:99-106.

32. Pinto M, Robine-Leon S, Appay MD, Kedinger M, Triadou N, Dussaulx E, et al. Enterocyte-like differentiation and polarization of the human colon carcinoma cell line Caco-2 in culture. Biol Cell 1983;47:323-30. 
33. Guix S, Bosch A, Ribes E, Martınez LD, Pintó RM. Apoptosis in astrovirus-infected Caco-2 cells. Virology 2004;319:249-61.

34. Figueiredo PMS, Furumura MT, Aidar-Ugrinovich L, Pestana de Castro AF, Pereira FG, Metze IL, et al. Induction of apoptosis in Caco-2 and HT-29 human intestinal epithelial cells by enterohemolysin produced by classic enteropathogenic Escherichia coli. Lett Appl Microbiol 2007;45:358-63.

35. Wu Z, Mirza H, Teo JD, Tan KS. Strain-dependent induction of human enterocyte apoptosis by Blastocystis disrupts epithelial barrier and ZO-1 organization in a caspase 3-and 9-dependent manner. Biomed Res Int 2019;63:1-11.

36. Jan G, Belzacq AS, Haouzi D, Rouault A, Metivier D, Kroemer G, et al. Propionibacteria induce apoptosis of colorectal carcinoma cells via short-chain fatty acids acting on mitochondria. Cell Death Differ 2002;9:179-88,

37. Atale N, Gupta S, Yadav UC, Rani V. Cell-death assessment by fluorescent and nonfluorescent cytosolic and nuclear staining techniques. J Microsc 2014;255:7-19.

38. Inouye S, Niizato T, Komiya I, Yuda Y, Yamada Y. Mode of protective action of fosfomycin against dibekacin-induced nephrotoxicity in the dehydrated rats. J Pharmacobiodyn 1982;5:941-50.

39. Ohtani I, Ohtsuki K, Aikawa T, Sato Y, Anzai T, Ouchi J. Protective effect of fosfomycin against aminoglycoside ototoxicity. ORL 1985;47:42-8.

40. Yanagida C, Ito K, Komiya I, Horie T. Protective effect of fosfomycin on gentamicin-induced lipid peroxidation of rat renal tissue. Chem
Biol Interact 2004;148:139-47.

41. Schweitzer VG, Dolan DF, Abrams GE, Davidson T, Snyder R. Amelioration of cisplatin-induced ototoxicity by fosfomycin. Laryngoscope 1986;96:948-58.

42. Tandy JR, Tandy RD, Farris P, Truelson JM. In vivo interaction of cisplatinum and fosfomycin on squamous cell carcinoma. Laryngoscope 2000;110:1222-4.

43. Yingjun L, Xiuqiang L, Chunwei L, Gexin L, Yaping J, Hao T. Selection of agents for prevention of cisplatin-induced hepatotoxicity. Pharmacol Res 2008;57:125-31.

44. Weitman SD, Kamen BA. Fosfomycin-friend or foe? Pediatric Hematol Oncol 1991;8:7-8.

45. Martínez G, Soraci AL, Tapia MO. Penetración de fosfomicina en células HEp-2 y su interacción con deoxinivalenol. Analec Vet 2011;31:23-7.

46. Martínez G, Pérez DS, Soraci AL, Tapia MO. Penetration of fosfomycin into IPEC J2 cells in the presence or absence of deoxinivalenol. PLoS One 2013;8:e75068.

47. Awad WA, Ghareeb K, Dadak A, Hess M, Böhm J. Single and combined effects of deoxynivalenol mycotoxin and a microbial feed additive on lymphocyte DNA damage and oxidative stress in broiler chickens. PLoS One 2014;9:e88028.

48. Katika MR, Hendriksen PJ, van Loveren H, Peijnenburg A. Characterization of the modes of action of deoxynivalenol (DON) in the human Jurkat T-cell line. J Immunotoxicol 2015; 12:206-16. 